\title{
Communication
}

[Comunicação]

\section{Cestodes Diphyllobothriidea parasitizing blackfin goosefish, Lophius gastrophysus Miranda-Ribeiro, 1915}

[Cestoides Diphyllobothriidea parasitos de peixe sapo-pescador, Lophius gastrophysus Miranda-Ribeiro, 1915]

\author{
M. Knoff ${ }^{1}$, S.C. São Clemente $^{2}$, M.C.G. Fonseca ${ }^{1}$, N.N. Felizardo ${ }^{1}$, R.M. Pinto ${ }^{1}$, D.C. Gomes ${ }^{1}$ \\ ${ }^{1}$ Laboratório de Helmintos Parasitos de Vertebrados - Instituto Oswaldo Cruz \\ Avenida Brasil, 4365 \\ 21045-900 - Rio de Janeiro, RJ \\ ${ }^{2}$ Faculdade de Veterinária - Universidade Federal Fluminense - Niteroi, RJ
}

The Lophius gastrophysus (Miranda-Ribeiro, 1915) species come from the State of Rio de Janeiro, Brazil, to Argentina and are the only representing Lophiiformes fishe found in the Brazilian Southeast region (Figueiredo and Menezes, 1978). The species is highly valuable in Brazil, mainly for exportation purposes and due to its great acceptance in the international market and the increasing opportunities for exportation to Europe.

Diphyllobothriidea cestodes, mainly the Diphyllobothriumspecies, as is widely known, is very important for public health, since they are responsible for the accidental settling of human diphyllobothriasis. In the intermediate fish hosts, the diphyllobothriasis can cause disease and death in natural conditions and breeding (Rahkonen et al., 1996). In humans, this zoonosis can appear after they feed on raw fish meat, or poorly cooked or smoked, or submitted to inadequate freezing conditions that favors the survical of the Diphyllobothrium larvae (Scholz et al., 2009). The classification of marine Diphyllobothrium species is somewhat confusing and the descriptions of Diphyllobothrium species of plerocercoids, whenever available, are incomplete (Andersen et al., 1987) and thus, require detailed morphological and morphometric studies of these larval forms. Diphyllobothrium latum (Linnaeus, 1758), D. dendriticum (Nitzsch, 1824) and D. pacificum (Nybelin, 1931) are the species referred in South America, causing diphyllobothriasis (Knoff et al., 2008) and their plerocercoid larvae, when compared, to show morphological differences other than the maximum total length. Other relevant aspects may be taken into consideration, such as the morphological aspect of the tegument surface, the length of the microtrichies, the format of the scolex, the degree of its invagination, the histological arrangement of the muscular bundles, and even the infection site (Dick and Poole, 1985).

Regarding the blackfin goosefish, despite its commercial importance, there are few data on the helminths of this host, including those that can be harmful to health or cause economic losses, since to date there is only a single record of Trypanorhyncha cestodes infecting this fish species (São Clemente et al., 2007).

The aim of this investigation was to identify the diphyllobothriid cestodes parasitizing specimens of L. gastrophysus in the State of Rio de Janeiro through the morphological and morphometric characterization with respective parasitic indexes related to prevalence, mean intensity, and mean abundance of infection.

From March 2000 to December 2005, 87 specimen of the blackfin goosefish Lophius gastrophysus were obtained from fishermen, markets, and fish exportation facilities in the municipalities of Cabo Frio (39 specimen), Niteroi (34 specimen), Duque de Caxias (six specimen), and Rio de Janeiro (eight specimen).

Recebido em 1 de agosto de 2010

Aceito em 23 de março de 2011

E-mail:knoffm@ioc.fiocruz.br 
After being purchased, the specimen were transported in isothermal containers with ice to the Laboratório de Helmintos Parasitos de Vertebrados, Instituto Oswaldo Cruz, Rio de Janeiro (LHPV/IOC/FIOCRUZ), to be investigated for helminths. The identification of fish was in accordance with Figueiredo and Menezes (1978). For recovery procedures, specimen were eviscerated; the organs and abdominal musculature were transferred to individual Petri dishes with a $0.65 \% \mathrm{NaCl}$ solution to be examined under a stereoscope microscope. The filets, obtained after an incision from near the opercula to the insertion of the caudal fin, were observed through a candling table. Cestodes were processed for study in accordance with Eiras et al. (2006). A larva was observed under a bright field Olympus BX-41 microscope and measures were related to body and scolex length and width and length of the bothrial swelling. The movements of one of the worms that was recovered alive were recorded by a digital still camera Sony MVC-FD92 to permit the tracking of its displacement. The middle portion of the body was embedded in paraffin, processed for histological studies, cross-sectioned $(7 \mu \mathrm{m}$ thick), stained with haematoxylin-eosin (HE), and observed under an Olympus BX-41 bright field microscope, for the analysis of internal structures of taxonomic interest. Another portion of the plerocercoid, with scolex and part of the body, was stained with Langeron's carmine and preserved as whole mount in Canada balsam. Photomicrographs were obtained in an Axiophot Zeiss bright field microscope. The taxonomic classification was based on Andersen and Gibson (1989) and Kuchta et al. (2008), and the parasitological indexes were according to Bush et al. (1997). A representative specimen of the cestode was deposited in the Coleção Helmintológica do Instituto Oswaldo Cruz (CHIOC), Rio de Janeiro, RJ.

Investigated fish specimen were parasitized with Diphyllobothrium sp. plerocercoids that were found in the intestinal serosa and abdominal cavity (Figure 1.1). One of the worms was recovered alive and showed intense activity when transferred to a Petri dish with a $0.65 \%$ $\mathrm{NaCl}$ solution (Figure 1.2), thus permitting the tracking of the specimen displacement (Figure $1.3 \mathrm{a}-\mathrm{d}$ ). The prevalence of the parasitism, mean intensity, and mean abundance of Diphyllobothrium sp. in the blackfin goosefish was $2.3 \%, 1$, and 0.02 , respectively.

Description of Diphyllobothrium sp., based on two specimen, with measurements, in one: body smooth, slightly rugose, $1.2 \mathrm{~cm}$ long, $0.1 \mathrm{~cm}$ wide. Scolex introverted, inconspicuous, under stereomicroscope, only observed under bright field microscopy, was $0.27 \mathrm{~mm}$ long, $0.75 \mathrm{~mm}$ wide (Figure 2.1), frontal glands present in the scolex, reaching up to $1 / 3$ of the body. Bothrial swelling $0.20 \mathrm{~mm}$ long. Microtriches hardly observed, 2.5-5 (3.75) $\mu \mathrm{m}$ (Figure 2.2). Transversal histological cross-sections in the middle region of the body showed a not so thick external epiderm, epidermic longitudinal musculature in a single layer, and parenchymal longitudinal musculature well developed in the anterior region, becoming less developed near the posterior portion (Figures 2.3-4).

Representative specimen was deposited in the CHIOC under no. 37182a (with both body extremities) and 37182b (HE histological sections of the middle of the body). This is the first report of Diphyllobothrium sp. plerocercoids infecting specimens of L. gastrophysus.

The observed morphological characteristics related to the small-sized; retracted scolex; the bothrial swellings; the inconspicuous microtriches; the frontal glands in the scolex, extending to $1 / 3$ of the body; and the epidermic longitudinal musculature in a single layer are very similar to those described in D. latum by Andersen and Gibson (1989).

Diphyllobothrium plerocercoids parasitizing teleost fishe in Brazil are poorly known. Recently, Knoff et al. (2008), observed larval Diphyllobothrium cestodes in the cusk-eel, Genypterus brasiliensis Regan, 1903. The larvae observed so far were similar to $D$. dendriticum, with a pseudo-segmented rugose body, with conspicuous developing genital apparatus in most of the specimen, that were 4.0-2.29 (1.30) cm long, 0.13-0.29 (0.17) cm wide, scolex 0.065$0.13(0.10) \mathrm{cm}$ long and 0.067-0.16 $(0.12) \mathrm{cm}$ wide, bothrial swelling 0.04-0.10 (0.16) cm long, microtriches 7.5-11.25 (10) $\mu \mathrm{m}$ long, different from the presently observed material shared closest characteristics with $D$. latum. 

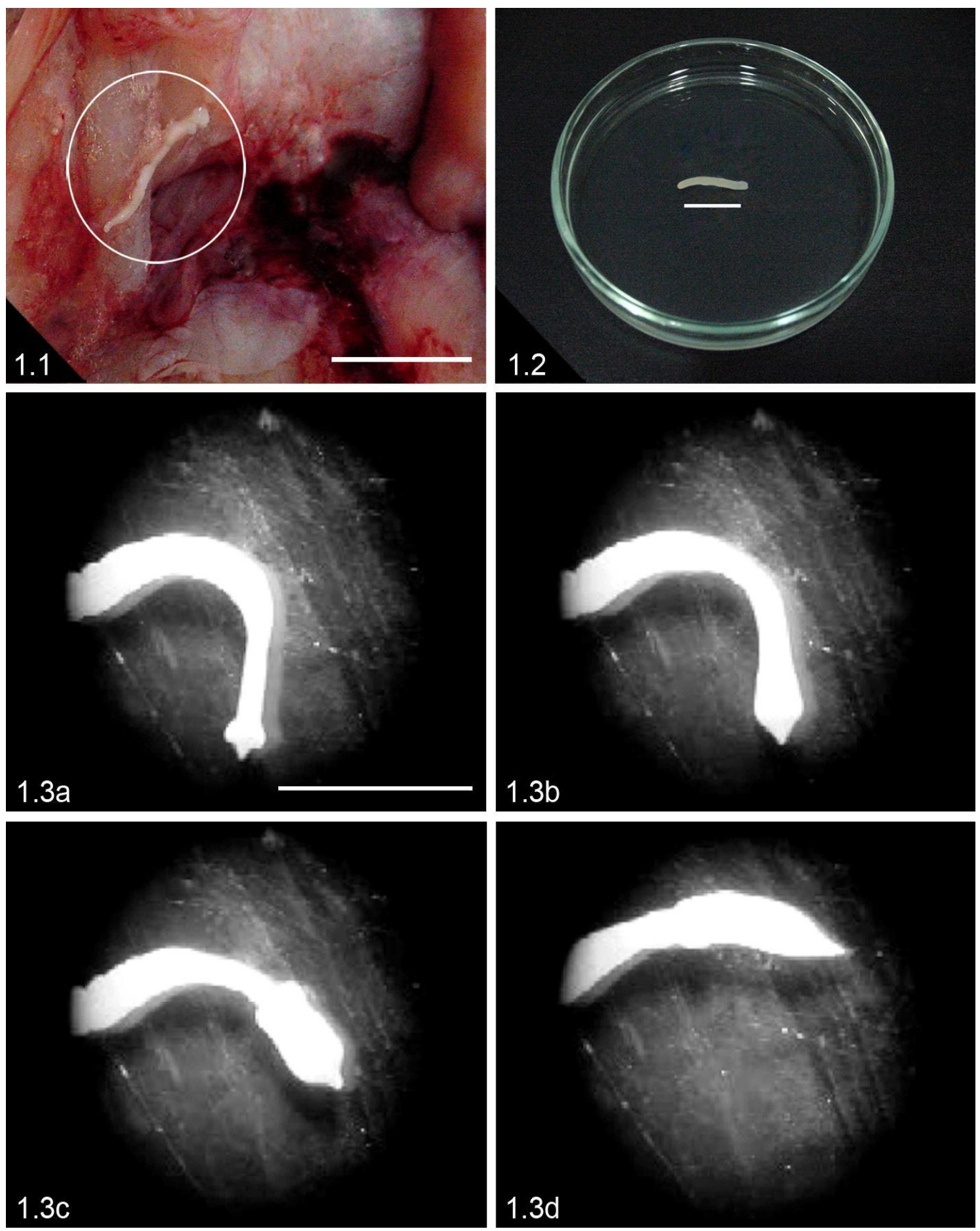

Figure 1. Plerocercoid of Diphyllobothrium sp. 1: Abdominal cavity with plerocercoid, bar $=1 \mathrm{~cm} .2$ : Petri dish with $0.65 \% \mathrm{NaCl}$ solution with the plerocercoid after the collect, bar $=1 \mathrm{~cm}$. 3: Sequence a-d permitting the tracking of plerocercoid displacent in a Petri dish with $0.65 \% \mathrm{NaCl}$ solution, bar $=1 \mathrm{~cm}$. 

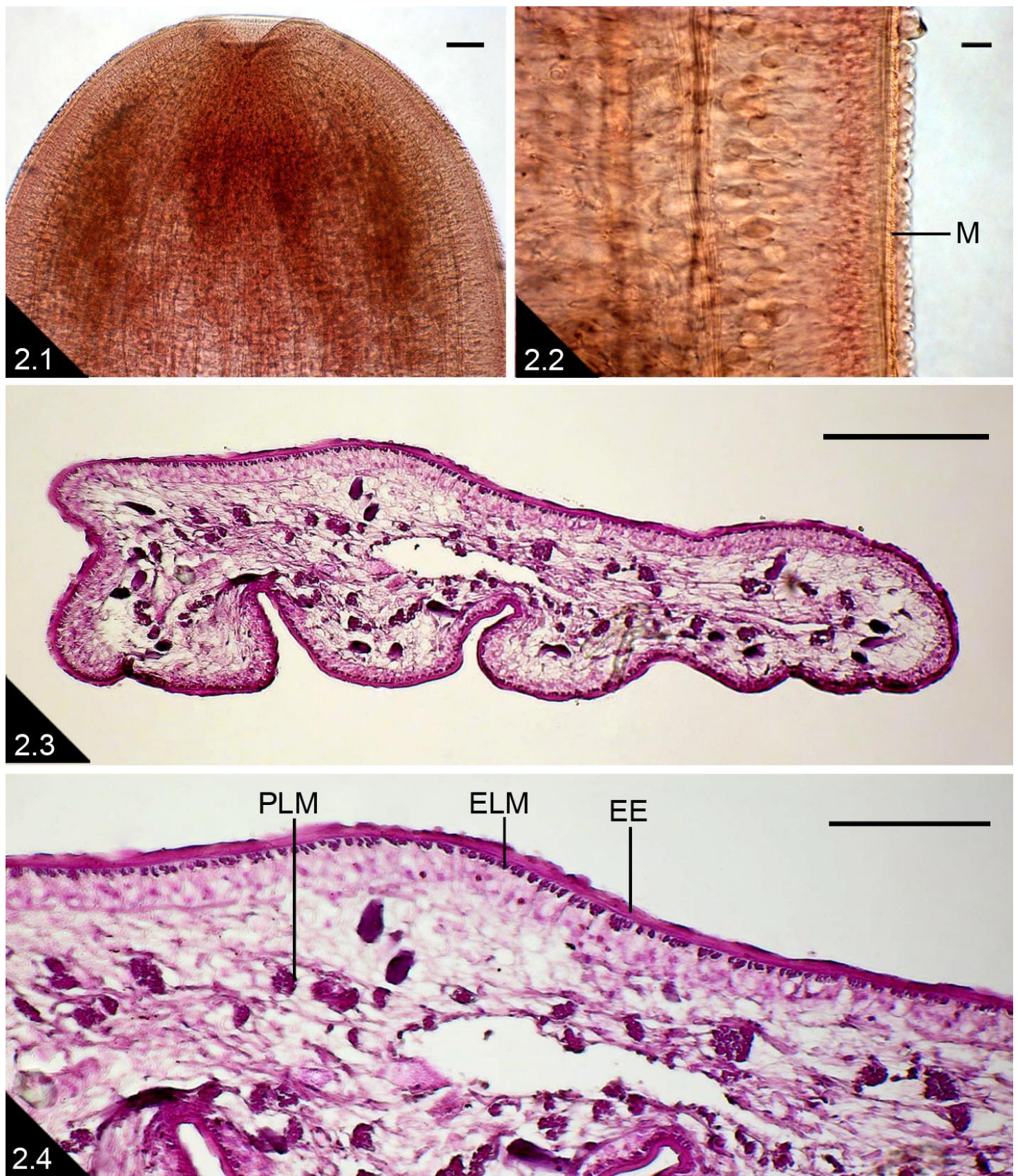

Figure 2. Plerocercoid of Diphyllobothrium sp. 1: Detail of anterior extremity showing introverted scolex, bar $=100 \mu \mathrm{m}$. 2: Detail of tegument indicating the microtriches $(\mathrm{M})$, bar $=20 \mu \mathrm{m}$. 3: Transversal histological cross-section in the middle region, bar $=200 \mu \mathrm{m}$. 4: Detail of 2.3 showing external epiderm (EE), epidermic longitudinal musculature (ELM), and parenchimal longitudinal musculature (PLM) well developed, bar $=200 \mu \mathrm{m}$.

Cases of human infection with diphyllobothriid cestodes of the Diphyllobothrium genus, mainly D. latum, have been reported in Brazil, with the statement that the transmission of diphyllobothriasis has occurred after the ingestion of raw, poorly cocked or smoked fish meat (Knoff et al., 2008; Mezzari and Wiebbelling, 2008). It reinforces the importance of the study of larval cestodes in Brazilian fishe, since in the present investigation, the 
plerocercoid larva was found alive in the host, thus permitting to observe the movement and extroversion of the scolex within the bothrial region, that became evident and pointed, Figure 1.3 a-d, making it very similar to the plerocercoid of $D$. latum that is shown in Andersen et al. (1987). The parasitological indexes obtained on that fish were very low, and the sites of infection that were found in musculature indicate zoonotic potential. Chai et al. (2005) reported that besides Japanese food, in several other countries the ingestion of raw fish is common, permitting that live plerocercoids infect humans. According to McCarthy and Moore (2000), the change of alimentary habits is to be considered a major risk factor, since it promotes the appearance and increase of zoonotic infections due to helminths. Thus, Diphyllobothrium sp. larvae parasitizing specimens of L. gastrophysus in Brazil can be harmful whenever fishe are inadequately ingested by consumers. Prevention methods related to human diphyllobothriasis already considered by Knoff et al. (2008) are priority and must be reported not only to the customers but also to fishermen and merchants.

Keywords: cestodes Diphyllobothriidea, Lophius gastrophysus

\section{RESUMO}

Entre os meses de março de 2000 e dezembro de 2005, 87 espécimes de L. gastrophysus foram obtidos de supermercados e empresas de exportação localizadas nos municipios de Cabo Frio, Niteroi, Duque de Caxias e Rio de Janeiro. Os peixes foram necropsiados, filetados e seus órgãos investigados para presença de helmintos. Dois espécimes (2,3\%) estavam parasitados por plerocecoides de Diphyllobothrium Cobbold, 1858 na cavidade abdominal e serosa do intestino, com intensidade média de um parasito por peixe e abundância média de 0,02, mostrando baixo potencial infectivo. Este é o primeiro registro de plerocercoides de Diphyllobothrium sp. no peixe sapo-pescador.

Palavras-chave: cestoides Diphyllobothriidea, Lophius gastrophysus

\section{ACKNOWLEDGEMENTS}

Thanks are due to veterinarian physicians Caroline Del Giudice de Andrada and Rodrigo do Espírito Santo Padovani for their technical help during their fellowship period at the LHPV/ IOC; to Dr. Francisco Carlos de Lima, from the Faculdade de Veterinária, Universidade Federal Fluminense, for supplying important information about the host; Ms. Heloisa Maria Nogueira Diniz from IOC Images Production and Treatment Service, for processing the figures; S.C.S.C., R.M.P. and D.C.G. were supported by the Conselho Nacional de Desenvolvimento Científico e Tecnológico (CNPq); M.C.G.F. was supported by the Fundação Carlos Chagas de Amparo à Pesquisa do Estado do Rio de Janeiro (FAPERJ).

\section{REFERENCES}

ANDERSEN, K.I.; GIBSON, D.I. A key to three species of larval Diphyllobothrium Cobbold, 1858 (Cestoda: Pseudophyllidea) occurring in European and North American freshwater fishes. Syst. Parasitol., v.13, p.3-9, 1989.
ANDERSEN, K.; CHING, H.L.; VIK, R. A review of freshwater species of Diphyllobothrium with redescriptions and the distribution of $D$. dendriticum (Nitzsch, 1824) and D. ditremum (Creplin, 1825). Can. J. Zool., v.65, p.2216-2228, 1987.

BUSH, A.O.; LAFFERTY, K.D.; LOTZ, J.M. et al. Parasitology meets ecology on its own terms: Margolis et al. Revisited. J. Parasitol., v.83, p.575-583, 1997.

CHAI, J.; MURRELL, K.D.; LYMBERY, A.J. Fish-borne parasitic zoonoses: status and issues. Int. J. Parasitol., v.35, p.1233-1254, 2005.

DICK, T.A.; POOLE, B.C. Identification of Diphyllobothrium dendriticum and Diphyllobobthrium latum from some freshwater fishes of central Canada. Can. J. Zool., v.63, p.196-201, 1985.

EIRAS, J.C.; TAKEMOTO, R.M.; PAVANELLI, G.C. Métodos de estudo e técnicas laboratoriais em parasitologia de peixes. Maringá: UEM Universidade Estadual de Maringá, 2006. 199p. 
FIGUEIREDO, J.L.; MENEZES, N.A. Manual de Peixes Marinhos do Sudeste do Brasil II. Teleostei (1). São Paulo: Museu de Zoologia, Universidade de São Paulo, 1978. 110p.

KNOFF, M.; SÃO CLEMENTE, S.C.; ANDRADA, C.D.G. et al. Cestoides Pseudophyllidea parasitos de congro-rosa, Genypterus brasiliensis Regan, 1903 comercializados no estado do Rio de Janeiro, Brasil. Rev. Bras. Cienc. Vet., v.15, p.28-32, 2008.

KUCHTA, R.; SCHOLZ, T.; BRABEC, J. et al. Suppression on the tapeworm order Pseudophyllidea (platyhelminthes: Eucestoda) and the proposal of two new orders, Bothriocephalidea and Diphyllobothriidea. Int. J. Parasitol., v.38, p.49-55, 2008.

McCARTHY, J.; MOORE, T.A. Emerging helminth zoonosis. Int. J. Parasitol., v.30, p.1351-1360, 2000.
MEZZARI, A.; WIEBBELLING, A.M.P. Diphyllobothriasis in Southern Brazil. Clin. Microbiol. Newsl., v.30, p.28-29, 2008.

RAHKONEN, R.; AALTO, J.; KOSKI, P. et al. Cestode larvae Diphyllobothrium dendriticum as a cause of a heart disease leading to mortality in hatchery-readed sea trout and brown trout. Dis. Aquat. Org., v.25, p.15-22, 1996.

SÃO CLEMENTE, S.C.; KNOFF, M.; LIMA, F.C. et al. Cestoides Trypanorhyncha parasitos de peixe sapo-pescador, Lophius gastrophysus Miranda-Ribeiro, 1915 comercializados no Estado do Rio de Janeiro, Brasil. Rev. Bras. Parasitol. Vet., v.16, p.37-42, 2007.

SCHOLZ, T.; GARCIA, H.H.; KUCHTA, R. et al. Update on the human broad tapeworm (genus Diphyllobothrium), including clinical relevance. Clin. Microbiol. Rev., v.22, p.146-160, 2009. 